\title{
Prevalence of Eclampsia and Its Maternal-Fetal Outcomes at Gandhi Memorial Hospital, Addis Ababa Ethiopia, 2019: Retrospective Study
}

This article was published in the following Dove Press journal: International Journal of Women's Health

\author{
Addisu Yeshambel Wassie (D) \\ Walellign Anmut iD \\ Department of Midwifery, College of \\ Health Science and Medicine, Wolaita \\ Sodo University, Wolaita Sodo, Ethiopia
}

Background: Eclamptic disorder during pregnancy is one of the common problems in subSaharan countries and forms one of the deadly triads along with hemorrhage and infection which complicates feto-maternal outcomes of pregnancy. So, the purpose of this study was to assess the prevalence of eclampsia and its maternal and fetal outcome in Gandhi Memorial Hospital, Addis Ababa Ethiopia, 2019.

Methods: A descriptive retrospective cross-sectional study was employed on a review of all cases of women who were delivered at Gandhi memorial Hospital from 1st of September 2017 to -last of August 2018. Data were analyzed using SPSS version 25 software. Descriptive statistics were used to calculate frequencies and percentages and data was presented using texts and, tables.

Results: Out of the total deliveries, the prevalence of eclampsia was found to be $6.2 \%$. In our experience of a very high rate of eclampsia, fortunately, we had only 3 maternal deaths out of the total cases. However, neonatal mortality and stillbirths had been extremely high: $41(22.1 \%)$ of stillbirths and $30.3 \%$ neonatal deaths (a total burden of $52.4 \%$ of perinatal mortality). About $70.8 \%$ had reported a history of prior pregnancy-induced hypertension and $73.5 \%$ induced their current pregnancy following eclampsia. From mothers who required interventions to terminate the pregnancy by induction, $47.8 \%$ ended by cesarean section secondary to non-reassuring fetal status $(29.2 \%)$. The majority $(91.9 \%)$ had taken magnesium sulfate for the management of convulsion and $86.5 \%$ had taken hydralazine for hypertension management. Abruption of the placenta (96.2\%), postpartum-hemorrhage (89.2\%), and HELLP syndrome (83.8\%) were major maternal adverse outcomes reported, and $22.1 \%$ of pregnancy was ended as stillbirth. Over $53.6 \%$ of delivered babies, $18.4 \%$ of neonates required admission to nursery/NICU referral.

Conclusion: The prevalence of eclampsia was relatively high, with corresponding high maternal and perinatal morbidity and mortality. Increasing early detection before pregnancy, antenatal screening, and the use of magnesium sulfate to control convulsions will reduce the disorder and associated morbidity and mortality for both mother and fetus.

Keywords: eclampsia, prevalence, feto-maternal outcome, Ethiopia

\section{Introduction}

Hypertensive disorders are the common complication occurring during pregnancy and it is one of the most leading causes of maternal and neonatal mortality in Ethiopia. ${ }^{1,2}$ Preeclampsia and eclampsia are major contributors to maternal and neonatal deaths in sub-Saharan African countries, which nearly accounts for
Correspondence: Addisu Yeshambel Wassie Email addisyes3@gmail.com
International Journal of Women's Health 2021:13 23I-237 
$10-15 \%$ of direct maternal deaths and nearly a quarter of stillbirths and newborn deaths. ${ }^{3}$

Eclampsia which usually occurs after 20 weeks of gestation $^{4,5}$ remains a major cause of death in lowincome countries and is highly associated with higher rates of adverse maternal and neonatal outcomes. ${ }^{6,7}$ It causes cardiovascular, cerebrovascular diseases, liver and renal problems, abruption of placenta, DIC, and hemolysis, HELLP-syndrome on mothers and neonatal/fetal complications like oligo-hydramnios, non-reassuring fetal heartbeat/status, preterm birth, low birth weight, severe asphyxia, stillbirth, and intrapartum death. ${ }^{8-10}$

The study conducted on the outcomes of severe preeclampsia/eclampsia among mothers in northwest Ethiopia revealed that the overall prevalence of severe preeclamptic/eclamptic mothers was $46.5 \% .^{10}$ In the study conducted in yekatit-12 teaching hospital, Addis Ababa, Ethiopia, eclampsia was accounted for $2.6 \%,{ }^{11}$ and studies also showed that complication was common in hypertensive disorders of pregnancy ${ }^{12,13}$ for example the study conducted in Mpilo central hospital, Bulawayo, Zimbabwe $^{14}$ revealed HELLP syndrome (9.1\%), maternal mortality (1.7\%) and $49.6 \%$ of the babies were lost through stillbirths and early neonatal deaths.

Prior studies have tried to determine the prevalence of hypertensive disorders ${ }^{1,9,15,16}$ and the government of Ethiopia in line with the ministry of health/who takes a commitment to reduce mortalities but specifically prevalence and its feto-maternal outcome in the study area is not studied yet. Therefore, the purpose of this study was to determine the prevalence of eclampsia and its maternal and fetal outcome in Gandhi Memorial Hospital, Addis Ababa Ethiopia, 2019 and the finding of this study will be significant for the improvement of health care setups for preventions as well as interventions of such problems/ bottlenecks.

\section{Methods}

\section{Study Area and Setting}

Gandhi Memorial Hospital is a hospital in central Addis Ababa, Ethiopia, Located in Kerkos- sub-city. Mahatma Gandhi Memorial Hospital, a 350 bedded hospital was laid early in 1994 and the building of this spacious hospital was completed in 1995. The hospital opened its doors to the public on the 7th of March 1997. The hospital was named after the well-respected Mohandas Karamch and Gandhi. Today the Hospital is operated by the Ministry of health and it has a total of 22 physicians, 140 nursing, and 45 Midwife staff. This hospital primarily cares for women and babies.

\section{Study Design and Period}

A retrospective cross-sectional study design was used to assess maternal outcomes of eclampsia. A Two Years retrospective hospital-based quantitative patient chart review study design from September 1/2017 to August 30/2018 was conducted at Gandhi Memorial Hospital, Addis Ababa Ethiopia, in 2019.

\section{Source Population}

All pregnant women who delivered (gave birth) and mothers were referred from other hospitals and, health centers for labor during the study period at Gandhi Memorial Hospital, Addis Ababa.

\section{Study Population}

All women who gave birth at Gandhi Memorial Hospital during the study period and, diagnosed to have eclampsia.

\section{Inclusion Criteria}

Mothers who were diagnosed with eclampsia and gave birth during the study period and also have a complete record were included.

\section{Exclusion Criteria}

Mothers who were diagnosed with eclampsia, and gave birth but incomplete charts.

\section{Dependent Variables}

Maternal and fetal outcome.

\section{Independent Variables}

Maternal age, parity, gestational age, admission blood pressure (BP), presence or absence of proteinuria on urine dipstick, seizure activity, and the mode of delivery. Lab values of interest included the complete blood count $(\mathrm{CBC})$, proteinuria, and $\mathrm{BP}$ readings during those antenatal visits.

\section{Sample Size Determination}

The sample size was determined using the single population proportion formula by considering proportion $(\mathrm{p})$ of eclampsia from the previously conducted study in Mettu Karl Referral Hospital showed that $19 \%,{ }^{17}$ the margin of error $(5 \%)$ and level of confidence $95 \%$, so 
$n i=\frac{(z \alpha / 2)^{2} p(1-p)}{d^{2}}=\frac{(1.96)^{2} 0.19(1-0.19)}{0.05^{2}}=236$

An adjustment formula was used and the total sample becomes 185 .

\section{Sampling Procedure}

Gandhi Memorial Hospital that offers maternal and delivery services were selected using a simple random technique and a review of all eclamptic cases was considered.

\section{Operational Definitions}

Pregnancy-induced hypertension $(\mathrm{PIH})$ : is when systolic blood pressure higher than $140 \mathrm{~mm} \mathrm{Hg}$ and two readings of diastolic blood pressure 90-110 $\mathrm{mmHg}$, 4 hours apart, after 20 weeks of gestation, and with proteinuria of $>300 \mathrm{mg} /$ 1 in 24 hours or up to $2+$ or more and with/without edema. Eclampsia: is systolic blood pressure higher than $140 \mathrm{~mm}$ $\mathrm{Hg}$ and diastolic blood pressure $90 \mathrm{~mm} \mathrm{Hg}$ or more after 20 weeks gestation with Convulsions and Proteinuria $2+$ or more high BP and plus seizure that cannot be attributed to some other cause or a woman with preeclampsia or Gestational HTN with seizure or coma.

HELLP syndrome: is a complication of pregnancy characterized by hemolysis, elevated liver enzymes, and a low platelet count.

Stillbirth: The birth of a dead fetus at 22 weeks or more and birth weight equal to or more than 500gms.

Neonatal death: The death of a baby that occur at less than 28 days of age with birth weight of $500 \mathrm{gms}$ and more.

Maternal death: The death of a woman while pregnant or within 42 completed days of termination, irrespective of duration and site of pregnancy, from any causes related to or aggravated by the eclamptic disorder or by its management but not due to accidental or incidental causes.

Maternal outcome: refers to mothers who had at least one of the following complications due to eclampsia (abruption of placenta, HELLP syndrome, DIC, acute renal failure, cardiac failure, post-partum hemorrhage, stroke, pulmonary edema, coagulopathy, and maternal death)

Fetal-outcome: refers to fetal/newborns who had at least one of the following complications due to eclampsia (low birth weight, stillbirth, intrauterine growth restriction, intrauterine fetal death, preterm birth, low APGAR score, birth asphyxia, and abortus)

Prevalence: quantifies the proportion of individuals in a population who have a disease at a specific time and provides an estimate of the probability.

\section{Data Collection Tool and Technique}

A pre-test was done on $5 \%$ of the total sample size and data was collected using a structured checklist which was adapted from the other study. ${ }^{13,17}$ The questionnaire was prepared in the English language and data was collected by the data collectors in the Gandhi memorial Hospital. All relevant information regarding demographic data, clinical findings, laboratory results, and each patient's outcome was collected. Data about antenatal care were extracted from the patient's history file and antenatal card.

\section{Data Analysis and Interpretation}

After the data have been collected, data were first checked for completeness, edited, and coded. The extracted data were cleaned; checked for accuracy and consistency, then it was entered into epi-data manager 4.6 and analyzed using SPSS version 25. Descriptive and analytic statistical procedures were employed.

\section{Ethical Consideration}

Ethical clearance letter was obtained from Addis Ababa University, School of Nursing and Midwifery, Department of midwifery $b / c$ the principal investigator Mr. Addisu Yeshambel was a student specializing in Maternity and Reproductive Health in Addis Ababa University by the time or in the year 2018/2019 who was sponsored by Wolaita Sodo University and he was assigned at Gandhi Memorial Hospital for clinical work and requested to do research entitled Prevalence of Eclampsia and its Maternal-fetal outcomes at Gandhi Memorial Hospital. An official letter of cooperation was taken from Gandhi memorial Hospital to the respective departments/case team. Patient informed consent was not required since all data were fully anonymized before data was accessed and that this study was conducted in accordance with the declaration of Helsinki.

\section{Result}

\section{Socio-Demographic Characteristics}

From the total of 2973 delivered mothers, 185 charts were reviewed during the study period. The prevalence of eclampsia became $6.2 \%$. The majority 57 (30.8\%) were in the age of 30-34 years with a mean age of $30.1( \pm 6.1)$ and around $27.6 \%$ were Muslim. From the total participants, $70(40 \%)$ were learned up to Secondary (9-12 grade) and more than half $(117(63.5))$ were married. 
Regarding their occupation, the majority (59.5\%) were unemployed (Table 1).

\section{Past Obstetrical, Medical, and Family History of Eclamptic Mothers}

Regarding past medical, obstetric, and family history, the majority $(60.5 \%)$ of them had diabetes miletus followed by chronic renal failure $(23.2 \%)$. From the total participants, more than three-fourth $(89.7 \%)$ had a history of pregnancy-induced hypertension and around $81 \%$ of them had reported a family history of hypertension (Table 2).

\section{Obstetrical History of Current Pregnancy of Eclamptic Mothers}

Out of the total participants, the majority 131 (70.8\%) reported as they were pregnant more than once followed by primigravida which was $29.2 \%$ and $47.0 \%$ were multiparas. Almost three-fourths $142(76.8 \%)$ of them were reported as regular ANC follow-up and $40.0 \%$ of them had at least one history of abortion. Around $56.8 \%$ had a prior history of hypertension. Regarding drugs given in their current pregnancy, almost all 170 (91.9\%) used

Table I Socio-Demographic Characteristics of Eclamptic Women Delivered at Gandhi Memorial Hospital, Addis Ababa, Ethiopia $2019(n=185)$

\begin{tabular}{|l|l|l|l|}
\hline Variables & Category/Group & Frequency & $\begin{array}{l}\text { Percentage } \\
\text { (\%) }\end{array}$ \\
\hline Age & $<24$ & 43 & 23.2 \\
& $24-29$ & 53 & 28.6 \\
& $30-34$ & 57 & 30.8 \\
& $>34$ & 32 & 17.3 \\
\hline Religion & Orthodox & 40 & 21.6 \\
& Muslim & 65 & 35.1 \\
& Protestant & 51 & 27.6 \\
& Catholic & 29 & 15.7 \\
\hline \multirow{2}{*}{ Educational } & Illiterate & 36 & 19.5 \\
& Elementary (1-8 grade) & 38 & 20.5 \\
& Secondary (9-12 grade) & 74 & 40.0 \\
& College and above & 37 & 20.0 \\
\hline \multirow{2}{*}{ Marital status } & Married & 117 & 63.2 \\
& Unmarried & 37 & 20.0 \\
& Divorced & 18 & 9.7 \\
& Widowed & 13 & 7.0 \\
\hline \multirow{5}{*}{ Occupation } & Employed & 75 & 40.5 \\
& Unemployed & 110 & 59.5 \\
\hline
\end{tabular}

Table 2 Past Obstetrical, Medical, and Family History of Eclamptic Mothers Delivered at Gandhi Memorial Hospital, Addis Ababa, Ethiopia $2019(n=185)$

\begin{tabular}{|l|l|l|}
\hline Variables & Frequency & $\begin{array}{l}\text { Percentage } \\
\text { (\%) }\end{array}$ \\
\hline Pregnancy-induced hypertension & 131 & 70.8 \\
Diabetes mellitus & 112 & 60.5 \\
Chronic renal disease & 43 & 23.2 \\
Heart disease class I (No limitation of activity) & 38 & 20.5 \\
Heart disease, Class 2-4 (any limitation in activity) & 7 & 3.8 \\
Hematological disorder (Chronic anemia) & 14 & 7.8 \\
Hepatitis & 7 & 3.8 \\
Seizure disorder & 15 & 8.1 \\
HIV/AIDS positive & 14 & 7.6 \\
Family history of hypertension & 81 & 43.8 \\
Family history of preeclampsia & 84 & 45.4 \\
\hline
\end{tabular}

magnesium-sulfate followed by hydralazine ( $86.5 \%)$, diazepam $(53 \%)$, and methyldopa $(50.3 \%)$ respectively (Table 3).

\section{Clinical Features (Chief Complaint (Other Than Pregnancy/Labor)) on} Admission and Delivery History

On admission, more than three fourth (93.5\%) had dizziness followed by headache $(85.9 \%)$, epigastric pain $(83.8 \%)$, and convulsion $(82.7 \%)$ respectively. From the total, more than half $(60.5 \%)$ had recorded diastolic blood pressure which was greater than $110 \mathrm{mmHg}$ on two occasions four hours apart and $54.6 \%$ had proteinuria +3 . Nearly three-fourths (73.5\%) started to induce labor to terminate their pregnancy secondary to fetal-distress (46.3\%) and $47.8 \%$ of mothers delivered by caesarian section followed by IUFD (29.2\%) and IUGR (27.2\%). Non-reassuring fetal status (29.2\%), IUFD (23.6\%), IUGR (20.8\%), and HELLP syndrome $(18.1 \%)$ were the main reasons reported for caesarian section respectively (Table S1).

\section{Maternal and Fetal Outcomes of the Eclamptic Disorders of Pregnancy}

Regarding feto-maternal complications related to eclampsia, the majority of them developed abruption of the placenta $(96.2 \%)$, postpartum hemorrhage $(89.2 \%)$, and HELLP syndrome $(83.8 \%)$ respectively. Of the total participants, $22.1 \%$ of them gave stillbirth and from the total $77.9 \%$ live births around $41.1 \%$ were asphyxiated and $18.4 \%$ were admitted to nursery/NICU. From live birth babies, nearly half (40.1\%) were low birth weight and the 
Table 3 Current Obstetrical History of Eclamptic Mothers Delivered at Gandhi Memorial Hospital, Addis Ababa, Ethiopia $2019(n=185)$

\begin{tabular}{|c|c|c|c|}
\hline Variables & Group & Frequency & $\begin{array}{l}\text { Percentage } \\
\text { (\%) }\end{array}$ \\
\hline \multirow[t]{3}{*}{ Gravidity } & Primigravida & 54 & 29.2 \\
\hline & Multigravida & 94 & 50.8 \\
\hline & Grandgravidity & 37 & 20 \\
\hline \multirow[t]{3}{*}{ Parity } & Primipara & 72 & 38.9 \\
\hline & Multi-para & 87 & 47.0 \\
\hline & Grand-para & 26 & 14.1 \\
\hline \multirow[t]{4}{*}{ Abortion } & Zero & 54 & 29.2 \\
\hline & One & 74 & 40.0 \\
\hline & Two & 43 & 23.2 \\
\hline & Greater than two & 14 & 7.6 \\
\hline \multirow[t]{3}{*}{ Gestational age } & Preterm & 105 & 56.8 \\
\hline & Term & 68 & 36.8 \\
\hline & Post-term & 12 & 6.5 \\
\hline \multirow{2}{*}{$\begin{array}{l}\text { Attended antenatal } \\
\text { follow }\end{array}$} & Yes & 142 & 76.8 \\
\hline & No & 43 & 23.2 \\
\hline \multirow[t]{4}{*}{ Number of children } & No children & 56 & 30.3 \\
\hline & One & 73 & 39.5 \\
\hline & Two & 28 & 15.1 \\
\hline & More than two & 28 & 15.1 \\
\hline \multirow[t]{2}{*}{ Prior history of $\mathrm{PIH}$} & Yes & $|3|$ & 70.8 \\
\hline & No & 54 & 29.2 \\
\hline \multirow{5}{*}{$\begin{array}{l}\text { Drugs given during the } \\
\text { current pregnancy }\end{array}$} & Methyldopa: & 93 & 50.3 \\
\hline & Nifedipine & 74 & 40.0 \\
\hline & Hydralazine & 160 & 86.5 \\
\hline & Magnesium sulphate & 170 & 91.9 \\
\hline & Diazepam: & 98 & 53.0 \\
\hline
\end{tabular}

majority $(48.2 \%)$ died within one week of delivery (Table S2).

\section{Discussion}

The study finds out, the prevalence of eclampsia and its maternal-fetal outcomes at Gandhi Memorial Hospital, Addis Ababa Ethiopia, 2019. In this study, the prevalence of eclampsia was found to be $6.2 \%$. This finding was greater than the study conducted in Africa, Asia, Latin America, and the Middle East ${ }^{18}$ which showed $0.28 \%$ cases, in Aminu Kano Teaching Hospital, Kano, Nigeria ${ }^{19}$ which was $1.2 \%$ cases, in a rural hospital in Western Tanzania $^{20}$ which showed $1.6 \%$ cases, a study at King Abdulaziz University Hospital. The difference might be due to the time gap difference, sample size, and the educational and awareness level difference. The study is also greater than the study conducted in Yekatit-12 Teaching Hospital, Addis Ababa, Ethiopia ${ }^{11}$ which accounted for $2.6 \%$. The difference might be due to the small sample size used in the study conducted in Yekatit12 Teaching Hospital, the time gap difference, and due to more case flow and client preference to Gandhi Memorial Hospital since it gives only maternal and child health service.

This study finding is less than the study conducted at four hospitals in separate Departments across Haiti ${ }^{6}$ which showed $23.3 \%$ cases, a tertiary care center in western Saudi Arabia ${ }^{16}$ showed only $8 \%$ cases, in low-resource settings, Mpilo Central Hospital, Bulawayo, Zimbabwe $(21.5 \%)^{14}$ in Albert Schweitzer (HAS) in Deschapelles, Haiti (30.7\%), ${ }^{21}$ in Mettu Karl Referral Hospital, Ethiopia (19\%), ${ }^{17}$ cases in Addis Ababa $(17.3 \%)^{12}$ and in Amhara Region referral hospitals, North West Ethiopia $(46.7 \%){ }^{10}$ This might be due to the large sample size difference, study setting, time gap difference/data collection time used in the former studies.

In this study finding, three women (1.6\%) died following eclamptic complications. This finding is in-line with the study conducted at Mpilo Central Hospital, Bulawayo, Zimbabwe, ${ }^{14}$ severe preeclampsia or eclampsia for the period January 1, 2016, to December 31, 2016, which showed $1.7 \%$ death cases. The finding is less than in a study conducted in a rural hospital in Western Tanzania $^{20}$ six women with eclampsia died (case fatality rate $11 \%$ ) and in the study conducted in Aminu Kano Teaching Hospital, Kano, Nigeria ${ }^{19}$ of maternal death $11.7 \%$. This difference might be due to the sample size difference, study setting, study time, or lack of awareness.

Regarding to maternal complication, postpartumhemorrhage $(89.2 \%)$, abruption of placenta $(96.2 \%)$, HELLP-syndrome $(83.8 \%)$, acute renal failure $(41.1 \%)$ pulmonary edema $(45.9 \%)$ and DIC $(40.0 \%)$ were the major complications identified related to eclamptic disorder. This finding is in-line with the study conducted in Aminu Kano Teaching Hospital, Kano, Nigeria ${ }^{19}$ (had pulmonary edema (1.7\%), had an acute renal failure (5\%) and 4.2\% had HELLP syndrome), in Mettu Karl Referral Hospital, Ethiopia, ${ }^{17}$ (12.4\% of HELLP complicated with renal failure $(6.6 \%)$, nine $(7.4 \%)$ with postpartum hemorrhage) and Addis Ababa ${ }^{12}$ (HELLP syndrome (39.5\%), pulmonary edema (17.5\%) and abruption placentae $(15.3 \%))$. This might be due to the fact that eclamptic 
disorder is highly associated with these complications and the socio-economic similarities between the participants.

In this study, the proportion of mothers delivered with cesarean section is $47.8 \%$. This is in-line with the study conducted in Aminu Kano Teaching Hospital, Kano, Nigeria ${ }^{19}$ which showed $55.8 \%$ of patients were delivered by cesarean section, in a rural hospital in Western Tanzania $^{20} 19 \%$ of women delivered by Caesarean section, in Amhara Region referral hospitals, North West Ethiopia $^{10}$ showed $27.9 \%$ delivered by cesarean section. This might be due to the fact that eclamptic disorder causes seizure/convulsion which is highly associated with fetal distress related placental-insufficiency and causes feto-maternal complications.

According to this study finding, stillbirth (22.1\%), birth asphyxia (41.1\%), low birth-weight (40.1\%), neonatal death $(30.3 \%)$, were the fetal outcomes/complications identified related to the eclamptic disorder and $18.4 \%$ of newly delivered babies were admitted to nursery/NICU. This finding is in-line with the study conducted in Aminu Kano Teaching Hospital, Kano, Nigeria ${ }^{19}$ (Stillbirth (22.5\%), birth asphyxia (39.1\%) and low birth weight in (25.8\%), in Amhara Regionreferral hospitals, North West Ethiopia $^{10}(28.1 \%)$ were stillbirths, $10.9 \%$ of neonates required resuscitation and $11.5 \%$ NICU referral), and in Addis Ababa, Ethiopia ${ }^{12}$ (stillbirths (30.2\%), prematurity (32.8\%), respiratory distress syndrome (37.9\%) and low birth weight $(30.2 \%))$

\section{Conclusion}

Even though various interventions were introduced in the country, the proportion of eclampsia cases in some governmental hospitals significantly increased. The rate of maternal complications during birth has slightly remained stable since the introduction of $\mathrm{MgSO} 4$ for eclampsia management; however, feto-maternal complications related to eclampsia cases have experienced a significant increase in overtime in the years. Neonatal complications arising from deliveries by eclamptic mothers also are a problem in the country even if it slightly declined over time. In conclusion, based on our research findings and using eclampsia as an indicator of maternal health, the current state of maternal health in some governmental hospitals and hospitals with similar nature in Ethiopia was far from achieving developmental goals and in need of big assignment for sustainable development goals. Attention should be focused on up to date and goal-oriented training for health professionals at the health centers and in the Hospitals to strengthening health facilities for early detection/prevention and management of feto-maternal complications related to eclampsia.

\section{Abbreviations}

HELLP, hemolysis, elevated liver enzyme levels, and low platelet levels; DIC, disseminated intravascular coagulation; SNNPR, Southern Nations, Nationalities and People's Region; IUGR, intra-uterine growth retardation; $\mathrm{ICU}$, intensive care unit; $\mathrm{C} / \mathrm{S}$, cesarean-section.

\section{Data Sharing Statement}

The data sets used and/or analyzed during the current study are available from the corresponding author on reasonable request and data request may be made and imposed on the corresponding author, email: addisyes3@gmail.com.

\section{Ethics Approval and Consent to Participate}

Ethical clearance was obtained from Addis Ababa University. All data were fully anonymized before data was accessed. Personal client information was not recorded, and after finishing the data collection the patients' document return to the card room, the information was used for study purposes only.

\section{Acknowledgments}

We would like to express our deepest heartfelt thanks to Addis Ababa University for allowing conduct this study. Our special thanks go to Gandhi Memorial Hospital staff for their support during the data collection process.

\section{Authors Contributions}

AY-was involved in the conception, design, analysis, interpretation, report, manuscript writing, design, analysis, interpretation, and report writing. WA- was involved in the design, analysis, and interpretation of the data. All authors read and approved the final manuscript. All authors made substantial contributions to conception and design, acquisition of data, or analysis and interpretation of data; took part in drafting the article or revising it critically for important intellectual content; agreed to submit to the current journal; gave final approval of the version to be published; and agree to be accountable for all aspects of the work. 


\section{Funding}

Addis Ababa University was involved in material support for data collectors, and expenditure for translation and transcription of questionnaires and hard copies.

\section{Disclosure}

The authors report no conflicts of interest in this work.

\section{References}

1. Berhe AK, Kassa GM, Fekadu GA, Muche AA. Prevalence of hypertensive disorders of pregnancy in Ethiopia: a systemic review and meta-analysis. BMC Pregnancy Childbirth. 2018;18(1):34. doi:10.1186/s12884-018-1667-7

2. Laine K, Murzakanova G, Sole KB, Pay AD, Heradstveit S, Räisänen S. Prevalence and risk of pre-eclampsia and gestational hypertension in twin pregnancies: a population-based register study. BMJ Open. 2019;9(7):e029908. doi:10.1136/bmjopen-2019-029908

3. Rawlins B, Plotkin M, Rakotovao JP, et al. Screening and management of pre-eclampsia and eclampsia in antenatal and labor and delivery services: findings from cross-sectional observation studies in six sub-Saharan African countries. BMC Pregnancy Childbirth. 2018;18 (1):346. doi:10.1186/s12884-018-1972-1

4. Grum T, Seifu A, Abay M, Angesom T, Tsegay L. Determinants of pre-eclampsia/eclampsia among women attending delivery services in selected Public Hospitals of Addis Ababa, Ethiopia: a case control study. BMC Pregnancy Childbirth. 2017;17(1):307. doi:10.1186/ s12884-017-1507-1

5. Backes CH, Markham K, Moorehead P, Cordero L, Nankervis CA, Giannone PJ. Maternal preeclampsia and neonatal outcomes. J Pregnancy. 2011;2011. doi:10.1155/2011/214365

6. Bridwell M, Handzel E, Hynes M, et al. Hypertensive disorders in pregnancy and maternal and neonatal outcomes in Haiti: the importance of surveillance and data collection. BMC Pregnancy Childbirth. 2019;19(1):208. doi:10.1186/s12884-019-2361-0

7. Goldenberg RL, Jones B, Griffin JB, et al. Reducing maternal mortality from preeclampsia and eclampsia in low-resource countries-what should work? Acta Obstet Gynecol Scand. 2015;94(2):148-155. doi:10.1111/aogs.12533

8. Kongwattanakul K, Saksiriwuttho P, Chaiyarach S, Thepsuthammarat K. Incidence, characteristics, maternal complications, and perinatal outcomes associated with preeclampsia with severe features and HELLP syndrome. Int $j$ Women's Health. 2018;10:371. doi:10.2147/IJWH.S168569

9. Kilembe FD Hypertensive disorders of pregnancy:: Prevalence, maternal complications and perinatal outcomes at Lilongwe Central Hospital, Malawi 2004.
10. Melese MF, Badi MB, Aynalem GL. Perinatal outcomes of severe preeclampsia/eclampsia and associated factors among mothers admitted in Amhara Region referral hospitals, North West Ethiopia, 2018. BMC Res Notes. 2019;12(1):1-6. doi:10.1186/s13104-0194161-z

11. Mengistu M, Kuma T. Feto-maternal outcomes of hypertensive disorders of pregnancy in yekatit-12 teaching hospital: a retrospective study. 2019.

12. Wagnew M, Dessalegn M, Worku A, Nyagero J. Trends of preeclampsia/eclampsia and maternal and neonatal outcomes among women delivering in addis ababa selected government hospitals, Ethiopia: a retrospective cross-sectional study. Pan Afr Med J. 2016;25(Suppl):2.

13. Mohammedseid SI, Megersa TN, Kumbi S, Ayalew MB. Maternal outcomes of pre-eclampsia in an Ethiopian Gynecologic Hospital. Ann Med Health Sci Res. 2017.

14. Ngwenya S. Severe preeclampsia and eclampsia: incidence, complications, and perinatal outcomes at a low-resource setting, Mpilo Central Hospital, Bulawayo, Zimbabwe. Int $j$ Women's Health. 2017;9:353. doi:10.2147/IJWH.S131934

15. Muti M, Tshimanga M, Notion GT, Bangure D, Chonzi P. Prevalence of pregnancy induced hypertension and pregnancy outcomes among women seeking maternity services in Harare, Zimbabwe. $B M C$ Cardiovasc Disord. 2015;15(1):111. doi:10.1186/s12872-015-0110-5

16. Subki AH, Algethami MR, Baabdullah WM, et al. Prevalence, risk factors, and fetal and maternal outcomes of hypertensive disorders of pregnancy: a retrospective study in Western Saudi Arabia. Oman Med J. 2018;33(5):409. doi:10.5001/omj.2018.75

17. Seyom E, Abera M, Tesfaye M, Fentahun N. Maternal and fetal outcome of pregnancy related hypertension in Mettu Karl Referral Hospital, Ethiopia. J Ovarian Res. 2015;8(1):10. doi:10.1186/s13048015-0135-5

18. Abalos E, Cuesta C, Carroli G, et al. Pre-eclampsia, eclampsia and adverse maternal and perinatal outcomes: a secondary analysis of the $\mathrm{W}$ orld $\mathrm{H}$ ealth $\mathrm{O}$ rganization Multicountry $\mathrm{S}$ urvey on $\mathrm{M}$ aternal and $\mathrm{N}$ ewborn H ealth. BJOG. 2014;121:14-24. doi:10.1111/14710528.12629

19. Jido TA. Ecalmpsia: maternal and fetal outcome. Afr Health Sci. 2012;12(2):148-152. doi:10.4314/ahs.v12i2.11

20. Mooij R, Lugumila J, Mwashambwa MY, Mwampagatwa IH, van Dillen J, Stekelenburg J. Characteristics and outcomes of patients with eclampsia and severe pre-eclampsia in a rural hospital in Western Tanzania: a retrospective medical record study. $B M C$ Pregnancy Childbirth. 2015;15(1):213. doi:10.1186/s12884-0150649-2

21. Raghuraman N, March MI, Hacker MR, et al. Adverse maternal and fetal outcomes and deaths related to preeclampsia and eclampsia in Haiti. Pregnancy Hypertens. 2014;4(4):279-286. doi:10.1016/j. preghy.2014.09.002

\section{Publish your work in this journal}

The International Journal of Women's Health is an international, peerreviewed open-access journal publishing original research, reports, editorials, reviews and commentaries on all aspects of women's healthcare including gynecology, obstetrics, and breast cancer. The manuscript management system is completely online and includes a very quick and fair peer-review system, which is all easy to use. Visit http://www.dovepress.com/testimonials.php to read real quotes from published authors. 